\title{
Nuevas tecnologías y divulgación científica: el caso de la app Hidden Valencia
}

\author{
New technologies and knowledge dissemination: the case of the Hidden \\ Valencia app
}

\section{Blanca Llanes Parra}

Institut Universitari d'Estudis de la Dona, Universitat de València, blanca.llanes@uv.es

\begin{abstract}
Resumen
Hidden Valencia es una aplicación móvil que se ha elaborado en el marco del proyecto europeo Public Renaissance: Urban Cultures of Public Space between Early Modern Europe and the Present (PURE), liderado por la Universidad de Exeter, y en el que participa la Universidad de Valencia, entre otras universidades europeas. El proyecto engloba a un equipo interdisciplinar de investigadores pertenecientes a los ámbitos de la historia del arte y de la arquitectura, de la historia social y de la historia cultural, trabajando en colaboración con museos, para poner en diálogo nuestra investigación como historiadores con las cuestiones relevantes del presente, indagando en las continuidades y rupturas que configuran los espacios públicos urbanos a lo largo del tiempo.
\end{abstract}

Hidden Valencia se integra dentro del grupo de aplicaciones móviles Hidden Cities. Inspiradas en el modelo de la pionera y galardonada app Hidden Florence, este conjunto de aplicaciones móviles invita al usuario a adentrarse en el pasado de cinco ciudades europeas (Deventer, Exeter, Hamburgo, Trento y Valencia), con la ayuda de un mapa histórico geolocalizado y de la mano de guías de los siglos XV al XVII. La aplicación Hidden Valencia, y en concreto su recorrido "Valencia agermanada", permite sumergirse en los dramáticos acontecimientos de la revuelta de las Germanías (1519-1522), con un guía muy especial, Josep, un ciego oracionero valenciano, miembro de la cofradía de la Vera Creu. Su objetivo es que el usuario pueda rastrear y descubrir las huellas del espacio público de la Valencia de principios del siglo XVI en la Valencia de hoy en día, enfatizando su conexión con los sucesos de la Germanía. En su recorrido por la ciudad, Josep desvela, además, cómo era la vida cotidiana de un ciego oracionero en la Valencia de la Edad Moderna.

Tomando como estudio de caso la aplicación móvil Hidden Valencia, en la presente comunicación se analizará el papel de las nuevas tecnologías en la 
difusión y divulgación del conocimiento histórico y artístico, subrayando la idoneidad del uso de medios locativos con esta finalidad didáctica y de compromiso público.

Palabras clave: Espacio público; humanidades digitales; patrimonio; turismo; Valencia.

\begin{abstract}
Hidden Valencia is a smartphone app created within the European project Public Renaissance: Urban Cultures of Public Space between Early Modern Europe and the Present (PURE), led by the University of Exeter, and which includes the University of Valencia together with other European universities. The project comprises an interdisciplinary team of art and architectural historians as well as social and cultural historians, working in collaboration with museums, with the aim of establishing a dialogue between their research and the key concerns of today, examining the continuities and ruptures of urban public spaces over time.
\end{abstract}

Hidden Valencia is part of the Hidden Cities smartphone apps. Inspired by the pioneering and award-winning app Hidden Florence, this set of apps invites users to delve into the past of five European cities (Deventer, Exeter, Hamburg, Trento, and Valencia), with the help of a geolocated period map and with historical guide characters from the fifteenth to the seventeenth centuries. The Hidden Valencia app, and specifically the "Revolutionary Road" trail, allows users to immerse themselves in the dramatic events of the Revolt of the Brotherhoods (1519-1522), with a very special guide, Josep, a blind street singer, member of Valencia's Vera Creu brotherhood of blind reciters of prayers. With this app, users can discover the traces of Valencia's past within today's urban public space, emphasizing its connection with the events of the revolt. In his tour of the city, Josep also reveals the daily life of a blind street singer in early modern Valencia.

By examining the Hidden Valencia app as case study, this paper will analyse the role of new technologies in humanities outreach initiatives, highlighting the suitability of the use of locative media with didactic purposes within public engagement strategies.

Keywords: Digital humanities; Public space; Cultural heritage; Tourism; Valencia. 


\section{Introducción}

Desde la primera década del siglo XXI, el desarrollo de la telefonía móvil, con la aparición de los teléfonos inteligentes (smartphones), ha dotado a los historiadores de nuevos medios para poder difundir sus investigaciones, siendo las aplicaciones móviles uno de estos instrumentos. La tecnología GPS presente en los dispositivos móviles hace posible, además, generar un contenido divulgativo enriquecedor para el usuario (Ritchie, 2013), contribuyendo también a profundizar en los nexos entre identidad y espacio (Souza e Silva y Frith, 2013; Barber, 2013; Nevola y Rosenthal, 2016). Tal como señalan Brett Oppegaard y Dene Grigar, el relato creado con este tipo de medios locativos permite "fomentar las interrelaciones entre cuatro entidades distintivas -entre el contenido y el medio; personas y espacio/tiempo; personas e información; y personas con otras personas", añadiendo como "los dispositivos móviles abren puertas para redescubrir lo olvidado, al tiempo que iluminan historias de nuestro pasado compartido" (Oppegaard y Grigar, 2013). Son estos, precisamente, los ejes que guían y los pilares sobre los que se asienta la app Hidden Valencia.

El recorrido "Valencia agermanada", el primero de los itinerarios creados para la aplicación móvil Hidden Valencia, ha sido diseñado para que el usuario pueda descubrir diferentes lugares de la ciudad que fueron testigos y tuvieron un papel destacado en el desarrollo de un episodio tan relevante e importante para la historia valenciana como fue la revuelta de las Germanías (1519-1522) ${ }^{1}$. En este viaje al pasado, la app ofrece al usuario dos herramientas para asistirle y orientarle a lo largo del recorrido: un mapa histórico geolocalizado y otro moderno, y un guía, Josep, un personaje ficticio del siglo XVI, ideado y moldeado a partir del estudio y del análisis de las fuentes históricas (Gomis, 2010 y 2019). Josep es miembro de la Cofradía de la Vera Creu de ciegos oraciones de la ciudad de Valencia, fundada en 1329 , y se dedica a recitar oraciones, a cantar y a contar historias en las calles valencianas a cambio de limosnas.

Nuestro guía acompaña al usuario de la app en un paseo por la Valencia de 1524, dos años después del final de la Germanías. En esos momentos, Josep se halla preparando un romance sobre la revuelta. Por eso solicita al visitante que se una a él en un recorrido que va desde las Torres de Serranos, puerta principal de Valencia en la época, hasta la plaza del Mercado. Josep quiere asistir a la ejecución pública de uno de los líderes agermanados que va a ser ajusticiado en esa misma plaza, con el objetivo de obtener información directa y de primera mano sobre la represión de la revuelta. Quiere estar presente en la ejecución, pero, lamentablemente, su guía, Pere, no puede acompañarle. De ahí que Josep invite al usuario a que sea su lazarillo y le guíe hasta la plaza del Mercado, parándose en diferentes puntos de la ciudad durante el recorrido, donde le irá revelando los secretos que se esconden tras ellos.

\footnotetext{
${ }^{1}$ Este trabajo ha sido elaborado en el marco del proyecto Public Renaissance: Culturas urbanas del espacio público en Europa entre la Edad Moderna y el presente, financiado por el Ministerio de Ciencia, Innovación y Universidades, con referencia PCI2019103749. El equipo de investigación del proyecto está integrado por Mónica Bolufer Peruga (investigadora principal), Pablo Pérez García, Jorge A. Catalá Sanz, Juan Francisco Pardo Molero, Daniel Muñoz Navarro y Blanca Llanes Parra (de la Universidad de Valencia), así como por Juan Gomis Coloma (de la Universidad Católica de Valencia).
} 
La elección de 1524 como fecha en la que situamos el relato del itinerario "Valencia agermanada" no es algo aleatorio ni azaroso, sino que viene determinada, en parte, por ser ese año el período del siglo XVI en el que se registró el mayor número de ejecuciones en Valencia, coincidiendo en el tiempo con el momento álgido de la represión contra los agermanados, siendo virreina de Valencia Germana de Foix (Catalá Sanz y Pérez García, 2000). Hay que tener presente que, con este primer itinerario de la app Hidden Valencia, lo que se persigue es que el usuario pueda rastrear o descubrir las huellas del espacio público de la Valencia de principios del siglo XVI en la Valencia de hoy en día, enfatizando su conexión con los sucesos de las Germanías, desde el estallido del conflicto hasta su represión. En este sentido, el relato de Josep nos ofrece información sobre los principales protagonistas de la revuelta (gremios, nobleza y representantes de la autoridad), las tensiones latentes que la hicieron estallar y el contexto político, social, económico y cultural en el que surge la misma. Además de ello, en su recorrido por la ciudad, Josep muestra al usuario cómo era la vida cotidiana de un ciego oracionero en la Valencia de la Edad Moderna.

Inspirada en la app Hidden Florence, creada por los historiadores Fabrizio Nevola y David Rosenthal no solo como un "experimento de investigación", sino también como una "herramienta pedagógica y un modo de hacer partícipe a un público lo más amplio posible en lo que en efecto es un recorrido alternativo de la ciudad" (Nevola y Rosenthal, 2016), la app Hidden Valencia pretende contribuir a la divulgación de la investigación histórica fuera del mundo académico, convergiendo aquí con disciplinas y espacios de conocimiento como son las humanidades digitales y la historia aplicada. En esta tarea juega igualmente un papel fundamental la puesta en valor y difusión del rico patrimonio histórico-artístico valenciano, vinculado a los sucesos y vivencias narradas por Josep, que se conserva actualmente bien in situ, o bien entre los fondos de museos y bibliotecas.

En los siguientes apartados se va a analizar el proceso de creación y elaboración de la app Hidden Valencia, haciendo, en primer lugar, una mención general al proyecto de aplicaciones móviles Hidden Cities, en el cual se enmarca, y a los objetivos que se persiguen con el mismo, antes de adentrarnos en el propio desarrollo y funcionamiento de la citada app. Con ello, se pretende examinar el papel de las nuevas tecnologías en la difusión y divulgación del conocimiento histórico y artístico, subrayando la idoneidad y validez del uso de medios locativos con esta finalidad didáctica y de compromiso público.

\section{La app Hidden Valencia y el proyecto Hidden Cities}

La creación de la app Hidden Valencia, y del recorrido de realidad aumentada "Valencia agermanada", se ha gestado en el marco del proyecto europeo Public Renaissance: Urban Cultures of Public Space between Early Modern Europe and the Present (PURE), financiado por la red Humanities in the European Research Area (HERA) y liderado por la Universidad de Exeter, en el que participa también la Universidad de Valencia junto con la Universidad de Groninga, la Universidad de Erlangen-Núremberg y el Instituto Histórico Italo-Germánico de Trento. En el caso del equipo español, su participación en el proyecto está financiada por 
la Agencia Estatal de Investigación, del Ministerio de Ciencia e Innovación del Gobierno de España (PCI2019-103749). El estudio de la configuración del espacio público en el entorno urbano de la Europa de la Edad Moderna, desde una perspectiva interdisciplinar y un enfoque comparativo, estableciendo conexiones entre el pasado y el presente, constituye el objeto y el eje temático en torno al cual gira este proyecto de investigación europeo.

Las desigualdades sociales y económicas, la pobreza, la violación de los derechos humanos, la corrupción, los abusos de poder y de autoridad, las guerras, la violencia de género, o la intolerancia religiosa y étnica, son algunas de las cuestiones claves que afectan y atañen a nuestra sociedad contemporánea. En este contexto, y ligado a estas preocupaciones globales, los espacios públicos urbanos se han revelado como lugares significativos de contestación, resistencia y negociación. Como resultado, estos escenarios se han convertido en símbolos icónicos de eventos cruciales y dramáticos de nuestra historia reciente, muchos de los cuales, además, han jugado un papel destacado contribuyendo a promover reformas en los ámbitos social, político y económico. En este sentido, y tal como plantea el investigador principal del proyecto, el profesor Fabrizio Nevola, nuestra investigación busca examinar los cambios y continuidades en los usos y funciones de los espacios públicos urbanos, poniendo el foco en la Europa de la Edad Moderna. Partiendo de los postulados de Henri Lefebvre (Lefebvre, 2013) y Michel de Certeau (Certeau, 1996) sobre la vida cotidiana y espacios urbanos, el proyecto busca examinar las formas en que estos espacios públicos fueron apropiados y se vieron afectados por las acciones tanto de las autoridades como del resto de la sociedad.

Tomando como estudio de caso principales de esta investigación cinco ciudades europeas (Deventer, Exeter, Hamburgo, Trento y Valencia), el proyecto persigue también contribuir a la difusión del conocimiento histórico a través del uso de nuevas tecnologías. En este contexto se enmarca la creación, en colaboración con la empresa de tecnología digital británica Calvium, del conjunto de aplicaciones móviles geolocalizadas Hidden Cities (2020), disponibles para su descarga gratuita en Apple Store y en Google Play Store, así como el desarrollo de la página web del proyecto (https://www.hiddencities.eu). Este grupo de aplicaciones móviles están basadas en la app Hidden Florence (2014), creada por Fabrizio Nevola, profesor de la Universidad de Exeter e investigador principal del mencionado proyecto PURE, junto con David Rosenthal, editor supervisor, a su vez, del contenido de las apps Hidden Cities.

Tal como revela el ejemplo de la app Hidden Florence, los medios locativos de esta naturaleza ofrecen un medio idóneo para comunicar la investigación histórica a un público amplio y una “nueva forma de acercarse y comprender los 'datos' históricos", a partir de la "experiencia sensorial (auditiva, visual, ambiental)" que proporcionan estos dispositivos tecnológicos digitales (Nevola y Rosenthal, 2016). La app Hidden Florence se diseñó como una audioguía, similar a las utilizadas en los museos, pero con la particularidad de poder ser activada por GPS, proporcionando, a su vez, una "experiencia más inmersiva" facilitada por la presencia de un guía (Giovanni, un trabajador textil del siglo XV) que acompaña al usuario en el itinerario (Nevola, 2016). 
Siguiendo el modelo de la app Hidden Florence, las aplicaciones móviles Hidden Cities, que funcionan igualmente como audioguías interactivas, aúnan investigación histórica y uso de nuevas tecnologías para sumergirse en la historia de cinco ciudades europeas (Deventer, Exeter, Hamburgo, Trento y Valencia) con la ayuda de un mapa histórico geolocalizado y uno moderno, y de la mano de personajes de los siglos XV al XVII. Las características de este conjunto de apps proporcionan un manejo sencillo, intuitivo y flexible. El usuario puede utilizar la app a medida que se mueve y se desplaza por la ciudad, por el itinerario propuesto, activando las historias con el GPS. No obstante, tampoco es necesario encontrarse in situ en estas ciudades para realizar dichos recorridos. En este último caso, el usuario lo que tiene que hacer es simplemente activar cada uno de los lugares incluidos en el itinerario, en el respectivo mapa histórico, pulsando dichos puntos en la pantalla de su móvil. El usuario también puede interrumpir el recorrido cuando lo desee, para retomarlo después. Estas aplicaciones móviles permiten, asimismo, intercalar el uso del mapa interactivo histórico con un plano actual de la ciudad.

En su recorrido por los itinerarios que ofrecen las apps, el usuario descubre cómo era la vida cotidiana en la época de estos personajes. Con un hilo argumentativo en torno a un tema concreto, en su narración los guías históricos informan sobre aspectos, datos y significados relevantes vinculados a los espacios públicos y al patrimonio histórico-artístico de estas ciudades en el pasado, que pueden pasar desapercibidos o permanecer ocultos en el presente. Además, en cada punto del recorrido, el usuario puede escuchar el audio "Descubre más", que completa el relato de los guías históricos desde la voz experta del historiador. Si se quiere profundizar aún más, la apps permiten redirigir al usuario a la página web del proyecto (https://www.hiddencities.eu), donde se pueden encontrar textos explicativos más extensos sobre el contenido de las apps y sobre los artefactos y objetos de la cultura material asociada a estos espacios públicos, muchos de los cuales se hallan custodiados en la actualidad en las colecciones de diferentes museos, archivos y bibliotecas, tanto de Europa como del resto del mundo.

Para conocer mejor el funcionamiento de estas aplicaciones móviles, se va a proceder a examinar, a continuación, la app Hidden Valencia, explicando no sólo en qué consiste y cómo funciona la misma, sino también mostrando cuál ha sido su proceso de elaboración y cuál es la historia que relata.

\section{3. "Valencia agermanada": espacio público, conflicto y memoria}

El caso específico de la app Hidden Valencia, y de su recorrido "Valencia agermanada", se centra en un acontecimiento concreto y decisivo de la historia de Valencia, la revuelta de las Germanías, para explorar su impacto en el espacio público de la ciudad, coincidiendo con la celebración del quinto centenario de la sublevación. Los inicios de este levantamiento se remontan al verano de 1519, momento en que estalla el conflicto en la ciudad de Valencia, cuando la difícil coyuntura económica y el creciente malestar social imperante hizo aflorar las tensiones que habían permanecido latentes, viéndose impregnado también de un fuerte 
sentimiento antimusulmán. Siguiendo los principales hechos que marcaron la revuelta de 1519 a 1522, este recorrido permite rastrear lugares y edificios emblemáticos de Valencia que fueron testigos del conflicto. Para ello, se ha adaptado a un formato asequible, y para un público amplio y diverso, la investigación existente sobre las Germanías, incluyendo la producción historiográfica de los grandes especialistas en esta materia, como Ricardo García Cárcel, Pablo Pérez García, Emilia Salvador Esteban, Rafael Narbona Vizcaíno, Vicent J. Vallés Borràs, Vicent Terol i Reig, Jorge A. Catalá Sanz y Juan Francisco Pardo Molero.

El itinerario, que comienza en las Torres de Serranos y finaliza en la Plaza del Mercado, discurre por diferentes puntos del centro histórico de la ciudad (Ciutat Vella), entre los que se encuentran los jardines del Palacio de la Generalitat, donde estaba ubicado el edificio de la antigua Casa de la Ciudad, demolida en 1860; la Puerta de los Apóstoles de la Catedral; el Palacio Arzobispal; la iglesia de Santa Catalina Mártir; y la Lonja de la Seda. Este recorrido no sigue un orden cronológico, ya que en su diseño optamos por priorizar el propio espacio urbano para hacer un itinerario ágil y dinámico, fácil de transitar y recorrer desde el lugar de partida hasta el destino final, ofreciendo un relato racional y coherente a lo largo del mismo. En cualquier caso, el usuario siempre tiene la opción de diseñar su propia ruta, o bien seguir el orden recomendado en la app.

El equipo de investigación del proyecto se ha encargado de diseñar el recorrido y de crear el personaje ficticio que actúa como guía (Josep), además de elaborar el conjunto de audios y textos de la app y de la página web, los cuales están disponibles en tres idiomas (español, valenciano e inglés). La grabación de los audios fue realizada por actores profesionales. Por su parte, la empresa británica Calvium y la estadounidense Axis Maps fueron las responsables de crear y desarrollar los sistemas de gestión de contenidos (CMS) de las apps y de la web Hidden Cities, respectivamente. La colaboración con estas empresas nos ha proporcionado herramientas (interfaces) sencillas para administrar y presentar nuestro contenido (en forma de textos, imágenes y audios), así como para definir el perímetro virtual del itinerario.

Como ya se ha mencionado, al igual que ocurre con la app Hidden Florence y el resto de apps Hidden Cities, el usuario dispone de un mapa histórico geolocalizado para navegar por el itinerario "Valencia agermanada". En el caso concreto de este recorrido, la app utiliza el plano de Valencia del pintor y cartógrafo italiano Antonio Mancelli, del año 1608. Dicho plano es, hoy por hoy, el mapa detallado más antiguo que se conoce de la ciudad. Fue realizado casi un siglo después de la revuelta de las Germanías. Orientado al sur y utilizando una vista axonométrica, el plano permite conocer cómo era la ciudad en 1608 (Benito Doménech, 1992). Hemos elegido el plano de Mancelli, como mapa histórico de la app Hidden Valencia, por su proximidad cronológica a los acontecimientos y vivencias relatadas por Josep. El trazado urbano que contiene, con sus calles, plazas y edificios más importantes, sería, por tanto, el más parecido al de la Valencia del siglo XVI, y resulta fácil superponerlo al mapa de Ciutat Vella. En la actualidad, existen dos ejemplares de este plano en el mundo: el del Museo Histórico Municipal de Valencia, cuya imagen reproducimos en la app, y el depositado en las colecciones de la Biblioteca Apostólica Vaticana (Barbeito, 2013 y Ramírez Aledón, 2017). 
El uso de este mapa histórico permite al usuario adentrarse en la Valencia de la Edad Moderna, proporcionándole un nuevo modo de aprendizaje y de conectar con el pasado de la ciudad y con el propio relato de Josep. En este sentido, y tal como señala Fabrizio Nevola para el caso de la app Hidden Florence, el contar con un recurso como un mapa histórico geolocalizado "historiza la experiencia de moverse por la ciudad", a la vez que posibilita que el usuario se distancie del entorno, para poder constatar mejor las diferencias existentes entre la ciudad actual y la del pasado (Nevola, 2016).

A través de la app, y a lo largo del recorrido, el usuario puede acceder a distintos niveles de información por diferentes vías, como ya se ha referido, a través de los audios de Josep y del apartado "Descubre más", y de la sección "Leer más" de la web, que contiene artículos breves con una pequeña bibliografía. Este tipo de contenido se ve complementado, además, por la presencia, tanto en la app como en la web, de un conjunto de imágenes relativas a los propios lugares y edificios que visita el usuario y a la cultura material vinculada a los mismos. Esta información de tipo visual es sumamente importante en determinados puntos del itinerario, como ocurre con la antigua Casa de la Ciudad, demolida en 1860; el Palacio Arzobispal, objeto de sucesivas reformas a lo largo del tiempo, que han propiciado un cambio radical en su fisonomía; y la plaza del Mercado. En estos casos, el usuario de la app puede conocer cómo eran estas edificaciones y emplazamientos en el pasado, a través de una serie de ilustraciones de época moderna y del siglo XIX.

Asimismo, la web ofrece al usuario, en cada punto del recorrido, una selección de objetos de naturaleza histórico-artística relacionados no solo con los espacios públicos visitados, sino también con los sucesos y experiencias evocadas en el itinerario de la app. Entre estas obras se incluye el retrato de la virreina Germana de Foix (de Gregorio Bausà o Antonio Bisquert), propiedad del Museo de Bellas Artes de Valencia, y el lienzo de Georges de La Tour Ciego tocando la zanfonía, perteneciente a la colección del Museo Nacional del Prado. Ha sido precisamente este último retrato el elegido como imagen para nuestro guía Josep, por sus similitudes con el músico callejero plasmado por Georges de La Tour en el referido cuadro.

En líneas generales, el recorrido "Valencia agermanada" permite explorar el centro histórico de la ciudad, recreando diferentes episodios de la revuelta rememorados oralmente por el guía de la app, Josep, testigo junto con su lazarillo Pere de los hechos que narra, y que, a su vez, son desarrollados en mayor profundidad tanto en los audios "Descubre más" de la app como en los textos del apartado "Leer más" de la página web. Estos sucesos históricos comprenden la entrada triunfal en Valencia del virrey Diego Hurtado de Mendoza en noviembre de 1521, así como el despliegue de fuerzas de los gremios en la recepción del virrey un año antes (Torres de Serranos); el acceso de los agermanados al gobierno de la ciudad (antigua Casa de la Ciudad); el alboroto de la Catedral o avalot de la Seu (Puerta de los Apóstoles); el asalto a la residencia del virrey y los ataques a las casas de los nobles (Palacio Arzobispal); las protestas de febrero de 1521, que desembocaron en la abolición de impuestos (Lonja de la Seda); y, finalmente, la represión de los agermanados durante el mandato de la recién nombrada virreina de Valencia, Germana de Foix (plaza del Mercado). 
El relato de Josep nos acerca, por tanto, a los sucesos de la revuelta desde la perspectiva de sus principales protagonistas: los gremios valencianos, la nobleza y el patriciado urbano, así como la propia autoridad real y sus representantes. En este recorrido, Josep también muestra al usuario las huellas visuales que han dejado los mismos en la arquitectura urbana, desde las esculturas de oficios gremiales de la Puerta de los Apóstoles a los escudos de armas de la ciudad y del Reino de Valencia, presentes en edificios como la Lonja de la Seda o en la Puerta de Serranos, revelando la importancia que tuvieron estos colectivos en la historia de la ciudad desde la Baja Edad Media. Josep hace igualmente partícipe al usuario de la importante transformación urbanística y arquitectónica experimentada por la ciudad durante los siglos XIV y XV. Esta empresa fue promovida por el gobierno municipal con el objeto de eliminar cualquier rastro de su pasado islámico y se materializó en la construcción de espléndidas edificaciones, como las referidas por Josep en el itinerario, erigidas como testimonio del poderío económico, comercial y financiero valenciano y de la "identidad, prestigio y orgullo cívicos" (Amadeo Serra, 1995).

Hay que destacar, por otro parte, que la elección, como guía histórico del itinerario "Valencia agermanada", de un personaje ficticio como Josep, no persigue únicamente acercar al usuario a los sucesos de la revuelta y al contexto político, social y económico en el que se inserta, vinculándolos con el espacio público urbano y los lugares que visita, ni tampoco mostrarle el rico universo cultural y artístico valenciano previo al estallido del conflicto. Josep, un ciego oracionero de la Cofradía de la Vera Creu de Valencia, se muestra como una figura ideal para poder enseñar a los usuarios cómo era el día a día y la experiencia vital de una persona con discapacidad visual en una urbe dinámica como la Valencia de principios del siglo XVI. A lo largo del recorrido, Josep va revelando detalles de su vida cotidiana y de su oficio, como ocurre, por ejemplo, en el primero de los puntos del itinerario (Torres de Serranos), cuando sugiere al usuario que dirija su vista al portal de entrada:

“Aquí estamos en la Puerta de Serranos, la entrada principal de Valencia, por donde llegan a la ciudad los viajeros como tú. Impresionante, ¿verdad? ¡Con sus magnificas torres! Aunque soy ciego de nacimiento, puedo describirla de memoria: siempre le pido a mi guía, Pere, que me cuente cómo son las cosas. Encima de la puerta se puede ver el escudo de la ciudad a ambos lados, y las armas del Reino de Valencia en el medio. Sin duda, la decoración en piedra le da a esta construcción militar una elegancia singular. Mis compañeros de la cofradía de ciegos cruzan a menudo esta puerta cuando se dirigen hacia el norte para rezar oraciones en los pueblos de alrededor".

La iglesia de Santa Catalina Mártir es el punto del recorrido elegido como el hipotético lugar donde Josep ejercería su oficio dedicado al rezo de oraciones, y en el que él mismo relata al usuario datos exclusivamente relacionados con su vida y con su trabajo. La información que se transmite al usuario en este punto concreto del itinerario, tanto a través de los audios de la app (Josep y "Descubre más") como del texto de la página web, hace especial hincapié en la importante función que llevaron a cabo los ciegos oracioneros durante la Edad Moderna en la transmisión de la cultura escrita a amplios segmentos de la población de la época, que en 
su mayoría era analfabeta (Gomis, 2019). Se trató de una labor de intermediación cultural, que el propio Josep reproduce en la actualidad a través de la app, al desvelar al usuario aquellos secretos y tesoros escondidos del patrimonio histórico-artístico de la ciudad de Valencia. Con ello, también se persigue ofrecer una imagen proactiva, y positiva, de la figura del ciego oracionero en la Edad Moderna, contribuyendo de este modo a ampliar nuestro conocimiento y percepción de la discapacidad en el pasado (Bolufer, Gomis y Llanes, en prensa).

\section{Conclusiones}

Sin duda, las nuevas tecnologías ofrecen al historiador nuevas formas con las que trabajar, interpretar el pasado y divulgar su investigación. Si se emplean con este último fin, como un instrumento divulgativo, tienen el potencial de llegar a un público extenso, al tiempo que pueden generar novedosas vías de conocimiento con la incorporación de múltiples elementos sensoriales, capaces de potenciar el aprendizaje. Así sucede con los medios locativos, como la aplicación móvil Hidden Valencia y el conjunto de apps del proyecto Hidden Cities, las cuales están inspiradas en la pionera y galardonada app Hidden Florence. Estas aplicaciones móviles han sido concebidas como una herramienta pedagógica, pero también constituyen un medio válido de investigación.

A la hora de diseñar el contenido de una aplicación móvil como la app Hidden Valencia, y más específicamente el de su itinerario "Valencia agermanada", el historiador se plantea una serie de cuestiones vinculadas con el objeto de estudio y el modo en que pretende difundirlo, teniendo en mente siempre al público receptor. En nuestro caso, las materias de investigación se han focalizado en la revuelta de las Germanías y en la figura del ciego oracionero como intermediario cultural, desde un planteamiento innovador, al ponerlas en relación con el espacio público y el patrimonio histórico-artístico de la ciudad de Valencia. Nuestra labor ha consistido, por una parte, en adaptar y transformar el trabajo académico sobre estos temas en un producto accesible para un público amplio, que no tiene por qué estar versado en estas temáticas. En este sentido, el formato de la app Hidden Valencia permite llegar a diferentes tipos de usuarios, los cuales pueden acceder a distintos niveles de información, en función de sus necesidades, inquietudes y conocimientos.

La aplicación móvil Hidden Valencia, con su recorrido de realidad aumentada, también fomenta un aprendizaje inmersivo. Los recursos de los que dispone el usuario a lo largo de todo el itinerario le permiten escuchar audios, visualizar imágenes y desplazarse a través de un mapa histórico geolocalizado, enriqueciendo de esta manera su interacción con los lugares que visita y con el pasado y favoreciendo la conexión entre las personas, los espacios públicos y los propios objetos de la cultura material asociada a los mismos. La app Hidden Valencia acerca así al usuario al extraordinario patrimonio arquitectónico y artístico valenciano, tanto el que se conserva en el lugar, como aquel que se halla custodiado en museos, bibliotecas, archivos u otro tipo de instituciones culturales, contribuyendo de este modo a la difusión de esta cultura material. 


\section{Referencias}

BARBEITO, J. M. (2013). "Juan Gómez de Mora, Antonio Mancelli y Cassiano dal Pozzo" en Archivo Español de Arte, vol. 86, issue 342, pp. 107-122.

BARBER, J. F. (2013). "Walking-Talking: Soundscapes, Flâneurs, and the Creation of Mobile Media Narratives" en Farman, J. The Mobile Story: Narrative Practices with Locative Technologies. Nueva York: Routledge, pp. 95-109.

BENITO DOMÉNECH, F. (1992). "Un plano axonométrico de Valencia diseñado por Manceli en 1608” en Ars Longa. Cuadernos de Arte, vol. 3, pp. 29-37.

BOLUFER, M., GOMIS, J. y LLANES, B. (en prensa). "Making Disability Visible in Digital Humanities: Blind Street Singers in Early Modern Valencia" en Rosenthal, D., Nevola, F. y Terpstra, N. Hidden Cities: Urban Space, Geolocated Apps and Public History in Early Modern Europe. Londres: Routledge.

CATALÁ SANZ, J. A. y PÉREZ GARCÍA, P. (2000). "La pena capital en la Valencia del Quinientos" en Salvador Esteban, E. Conflictos y represiones en el Antiguo Régimen. Valencia: Universitat de València, pp. 21-112.

CERTEAU, M. de (1996). La invención de lo cotidiano. Vol. 1. Artes de hacer. Nueva edición establecida y presentada por L. Giard. Traducción de A. Pescador. México, D.F.: Universidad Iberoamericana, Departamento de Historia.

GOMIS, J. (2010). "Intermediarios entre el texto y su público: la cofradía de pobres ciegos oracioneros de Valencia” en Castillo Gómez, A. y Amelang, J. S. Opinión pública y espacio urbano en la Edad Moderna. Gijón: Trea, pp. 301-317.

GOMIS, J. (2019). "Pious voices: Blind Spanish prayer singers" en Renaissance Studies, vol. 33, issue 1, pp. 42-63.

LEFEBVRE, H. (2013). La producción del espacio. Prólogo de I. Martínez Lorea. Introducción y traducción de E. Martínez Gutiérrez. Madrid: Capitán Swing.

NEVOLA, F. y ROSENTHAL, D. (2016). "Locating experience in the Renaissance city using mobile app technologies. The Hidden Florence project" en Terpstra, N. y Rose, C. Mapping Space, Sense, and Movement in Florence. Historical GIS and the Early Modern City. Londres: Routledge, pp. 187-209.

NEVOLA, F. (2016). "Microstoria 2.0: Geo-locating Renaissance Spatial and Architectural History" en Estill, L., Jakacki, D. y Ullyot, M. Early Modern Studies after the Digital Turn. Toronto: Iter Press, Arizona Center for Medieval and Renaissance Studies, pp. 261-284.

OPPEGAARD, B. y GRIGAR, D. (2013). “The Interrelationships of Mobile Storytelling: Merging the Physical and the Digital at a National Historic Site" en Farman, J. The Mobile Story: Narrative Practices with Locative Technologies. Nueva York: Routledge, pp. 17-33.

RAMÍREZ ALEDÓN, G. (2017). "El plano de València de Antonio Manceli (1608): noticias, vicisitudes y aclaraciones de un documento excepcional, pero no único" en Pasiones bibliográficas II. Valencia: Societat Bibliogràfica Valenciana Jerònima Galés, pp. 165-176. 
RITCHIE, J. (2013). “The Affordances and Constraints of Mobile Locative Narratives” en Farman, J. The Mobile Story: Narrative Practices with Locative Technologies. Nueva York: Routledge, pp. 53-67.

SERRA DESFILIS, A. (1995). "La imagen de la ciudad: prestigio e identidad urbana en Valencia (1350-1480)" en Sociedad urbana. Revista de estudios urbanos, vol. 2, pp. 69-85.

SOUZA e SILVA, A. de y FRITH, J. (2013). "Re-Narrating the City Through the Presentation of Location" en Farman, J. The Mobile Story: Narrative Practices with Locative Technologies. Nueva York: Routledge, pp. 34-49. 